القدرة التنافسية لأهم محاصيل الفاكهة المصرية في أسواق دول إتحاد البريكس

عزه نبيه عبدالله، مصطفي محمد السعدني، ألفت علي ملوك، جابر عبدالعاطي محمد1 1

وعدم وجود ميزة سعرية له مقارنة بأسعار نامبيا. وفي السوق الصيني تبين وجود ميزة سعرية للعنب المصري مقارنة بأسعار لنيار

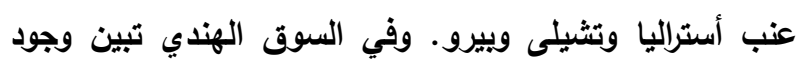
ميزة سعرية للعنب المصري مقارنة بأسعار عنب أمريكا وبيرو وتيرو والصين.

وتثير نتائج الاراسة إلى إرتفاع قيمة معامل الميزة النسبية الظاهرة لمصر في تصدير البرتقال والمقدر بحوالي 23.9 خلال

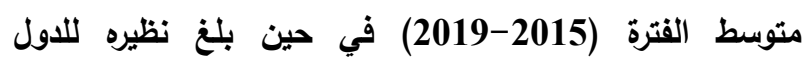

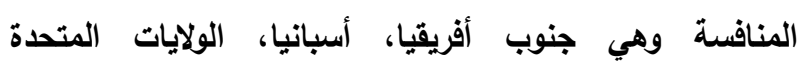

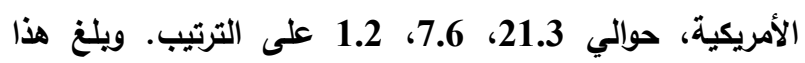
المعامل للغب المصري حوالي 7.2 في حين كان نظيره للاول

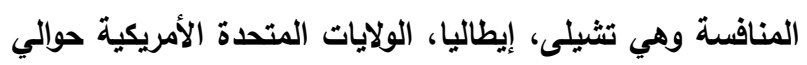

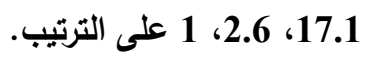
ويتقدير معدل إخترلق السوق للبرتقال والعب المصري خلال متوسط الفترة (2015-2019) تبين أن قيمته أكبر من الواحد الصحيح للبرتقال المصري في أسواق كل من روسيا وجنوب آنيا أفريقيا والصين وهي تغنى سهولة إخترلق البرتقال المصري لتلتك

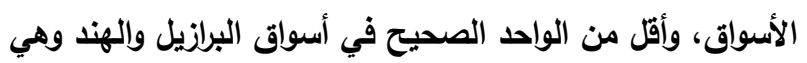

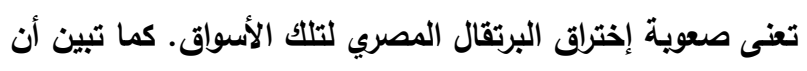
قيمة معامل إخترلق السوق للعنب المصري أكبر من الواحد

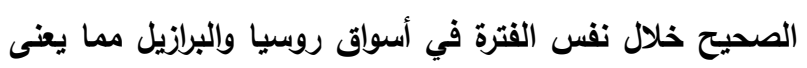

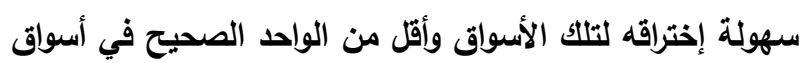
جنوب أفريقيا والصين والهند مما يغنى صعوية إختراقه لتلتك

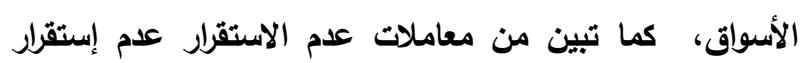

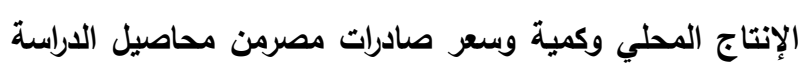

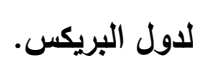

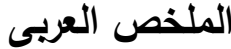

استهاف البحث التعرف على الموقف الإنتاجي لكل من البرتقال والعب في مصر والأهمية النسبية للصادرات المصرية

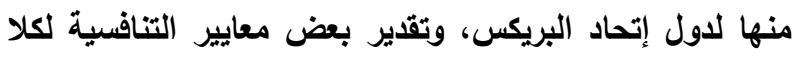

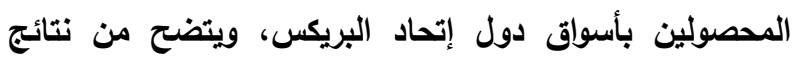
الدارسة أن الإنتاج المصري من البرتقال أخذ اتجاها تزايديا

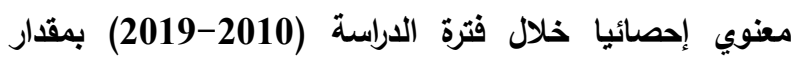
96.5 ألف طن سنويا وأخذ إنتاج العنب اتجاها تزايديا معنوي إحصائيا خلال نفس الفترة مقاره 21.8 ألف طن سنويا. ويتضح من تقير معايير التنافسية للبرتقال والعنب المصري

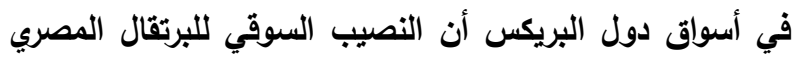
في أسواق كل من روسيا، الصين، الهند، البرازيل، جنوب أفريقيا

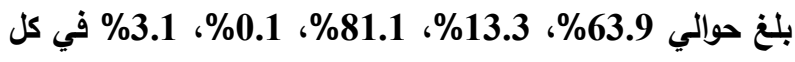

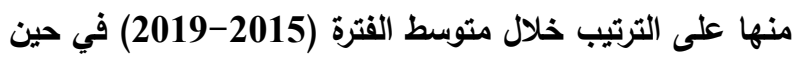
بلغ النصيب السوقي للغب المصري في كل منها حوالي 5.2\%،

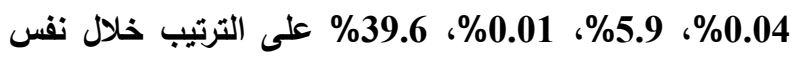
الفترة وهو ما يثير إلى تدني النصيب السوقي للبرتقال المصري

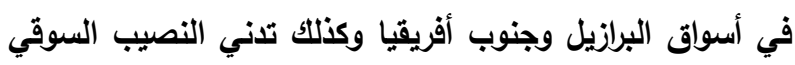
للعب المصري في أسواق الصين والبرازيل. ويتضح من معايير التنافسية السعرية وجود ميزة سعرية للبرتقال المصري في أسواق دول البريكس بالمقارنة بأسعار

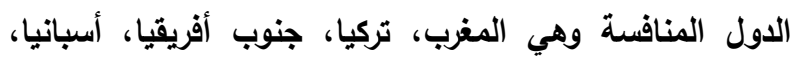

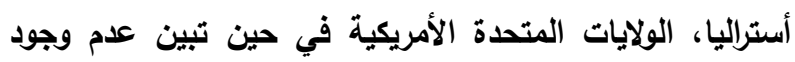
ميزة سعرية للغب المصري في تلك الأسواق مقارنة بأسعار كل فل فئل

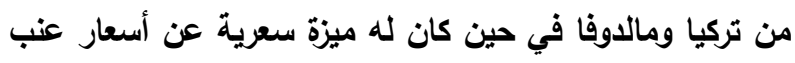
تثيلى في السوق الروسي. وفي سوق جنوب أفريقيا تبين وجود ميزة سعرية للعب المصري مقارنة بأسعار كل من أسبانيا وزامبيا

معرف الوثيقة الرقمى: asejaiqjsae.2021.18941310.21608

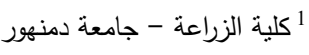
استلام البحث فى05 يوليو 2021، الموافقة على النشر فى 11 أغسطس 2021 
وقد بلغت كمية الصادرات المصرية من البرتقال عام 2019 حوالي 1.817 مليون طن ومن العنب حوالي 1.595 مليون طن وبلغت قيمة كل منها حوالي 656.6، 234.9 مليون دولار بأهمية نسبية بلغت حوالي 12.15\%، 4.35\% من قيمة إجمالي الصادرات الزراعية خلال نفس العام لكل منها على الترتيب.

وتمثل كمية الصادرات المصرية من البرتقال حوالي

40.8 من إنتاجه المحلي خلال منوسط الفترة (2010-

2019) في حين تمثل كمية الصادرات المصرية من العنب حوالي 11.7\% من إنتاجه المحلي خلال نفس الفترة.

\section{المشكلة البحثية}

تتمنل مشكلة البحث في ضعف نسبة الصادرات من الإنتاج المحلي للحاصلات البستانية بصفة عامة وحدة التقلبات السنوية في كمية وأسعار تصديرها للأسواق الخارجية وذلك نظرا للمنافسة الثديدة في تلك الأسواق، هذا بالإضافة

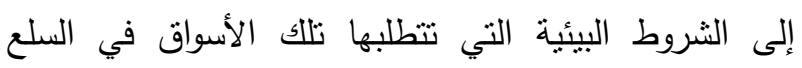
الواردة إليها وكذلك ما يترتب على التكتلات الإقتصادية من مزايا تفضيلية للدول الأعضاء فيها وهو ما يترتب عليه ضعف النصيب السوقي لكثير من صادرات الحاصلات البستانية بتلاك الأسواق وضعف مساهمتها في تقليل العجز في الميزان التجاري الزراعي المصري.

\section{الأهداف البحثية}

إستهدف البحث بصفة أساسية التعرف على الموقف النتافسي لكل من البرتقال والعنب المصري في أسواق دول تكتل البريكس وهي روسيا، الصين، الهند، البرازيل، جنوب أفريقيا وذلك بغية التعرف على السبل التي يمكن من خلالها زيادة النصيب السوفي لمصر من صادرات تلاك المحاصيل بتلك الأسواق وذلك من خلال الأهداف الفرعية التالية:
الكلمات المفتاحية: البريكس- التنافسية- أسواق - البرتقال -

العنب.

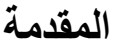

لاثك أن التعرف على الموقف التتافسي للسلع الزراعية المصرية بأسواقها الخارجية والعمل على رفع قدرثها التتافسية يعتبر من متطلبات تتمية الصادرات الزراعية والتي يمكن من خلالها تقليل العجز في الميزان التجاري المصري، كما ترجع أهمية دراسة القدرة التتافسية للسلع الزراعية في الأسواق الخارجية إلى التغيرات العالمية المتسارعة والتي تؤدى دائما إلى زيادة المنافسة بين الدول للحصول على النصيب الأكبر من الأسواق العالمية والذي يتوقف على ما يتمتع به الإنتاج المحلي من أي سلعة من مزايا نتافسية والتي هي محصلة العديد من العوامل.

والبريكس إصطلاح يحمل بإختصار الأحرف الأولى للكلمة الإنجليزية BRICS وهي مكونة من الأحرف الأولى لإحلى لأسماء الدول الخمس من كل منها: البرازيل (Brazil)، روسيا (Russia)، الهند(India)، الصين (China)، وجنوب أفريقيا (South Africa) في صورة إتحاد جمركي ويمنل الإتحاد الجمركي للبريكس المستوى الثاني من مستويات التكتل الاقتصادي الإقليمي والتي أقلها من حيث التكتل الاقتصادي منطقة التجارة الحرة، وثانيها الإتحاد الجمركي، وثالثها السوق المشتركة، ورابعها وهي أعلى مستوى للتكتل الاقتصادي هي الإتحاد

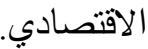

ويمتلك إتحاد أو تجمع البريكس مزايا عديدة حيث يعتبر سوق كبير نظرا لكبر عدد سكانه ومصدر للتكنولوجيا الحديثة، وترتبط مصر بدول هذا الإتحاد بعلاقات جيدة خاصة روسيا والصين والهند حيث يتم في هذا الإتحاد إلغاء الرسوم الجمركية والقيود الكمية فيما بين الدول الأعضاء وبتعريفة جمركية موحدة يتم تطبيقها على السلع المستوردة

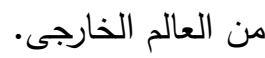


وقد استتدت الدراسة إلى البيانات الثانوية المنشورة وغير

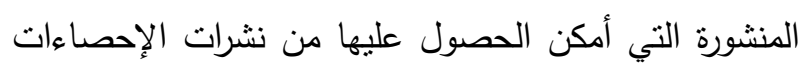

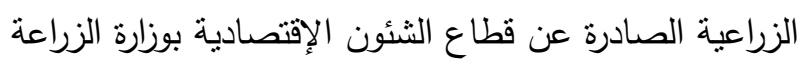

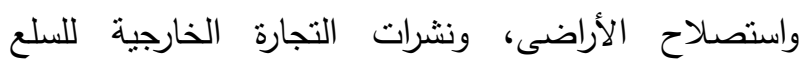
الزراعية الصادرة عن الجهاز المركزي للتعبئة العامة الإنة والإحصاء، ومختلف المواقع الالكترونية على الثبكة الدولية

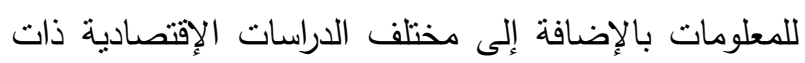
الصلة بموضوع الدراسة. الوضع الراهن لإنتاج البرتقال والعنب في مصر :

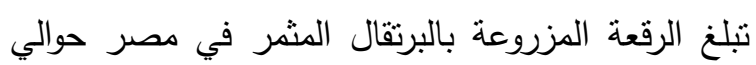
292 ألف فدان ومن العنب حوالي 174.7 ألف فدان وتندئل كل منها نحو 20.11\%، 12.03\% من إجمالي المساحة المزروعة بمختلف أنواع الفاكهة في مصر عام 2019 على منى إجمالي

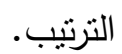

ويتضح من جدول (1) أن المساحة المزروعة بكل من

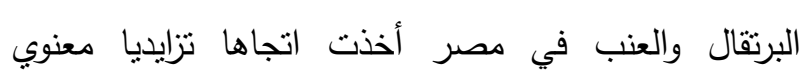
إحصائيا مقداره حوالي 8 ألف فدان للبرتقال وحوالي 2.9 ألف بـن

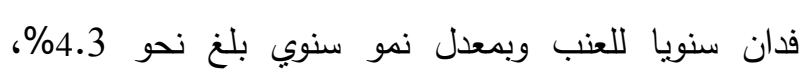

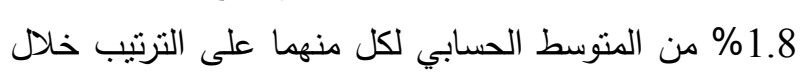
الفتزة (2010 - 2019).

كما أخذت الإنتاجيه الفدانية للبرتقال اتجاها تزايديا معنوي

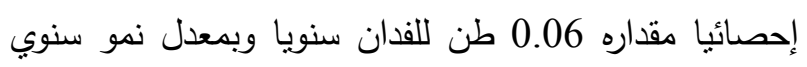
0.6\% من المنوسط الحسابي للإنتاجية المقدر خلال فترة الدراسة بحوالي 10.08 طن للفدان، في حين أخذت الإنتاجية الفدانية للعنب اتجاها تتاقصيا غير معنوي إحصائيا خلال

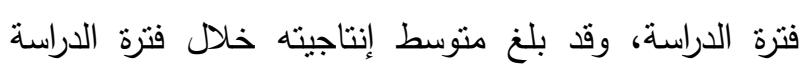
حوالي 9.25 طن للفدان.
1.التعرف على الموقف الإنتاجي لكل من البرتقال والعنب في مصر من حيث معدل نمو الإنتاج ومدى إستقراره

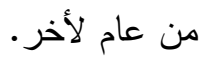

2.التعرف على الأهمية النسبية للصادرات المصرية من

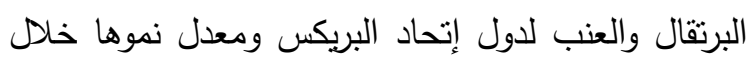
فترة الدراسة.

3.تقدير بعض معايير التتافسية للمحاصيل التصديرية

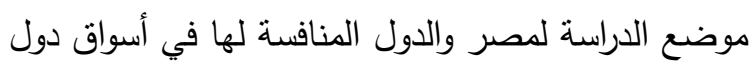

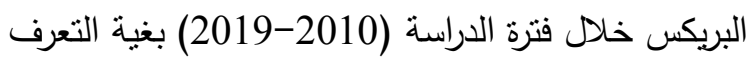

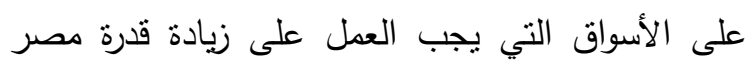

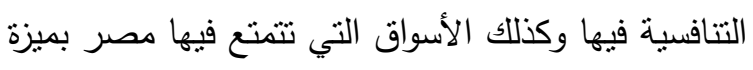
نسبية في تصدير البرتقال والعنب. 4.وضع تصور لكيفية زيادة النصبي السوقي لصادرات مصر من البرتقال والعنب في أسواق دول البريكس. الأسلوب البحثى ومصادر البيانات

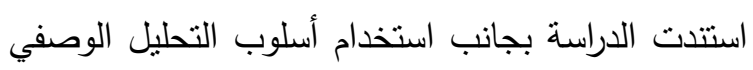
إلى بعض الأساليب الإحصائية المتمنلة في أسلوب الإنحدار البسيط للتعرف على معدلات النمو لـختلف المتغيرات

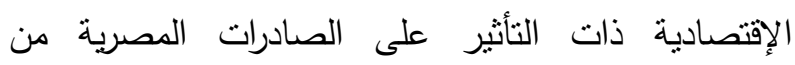

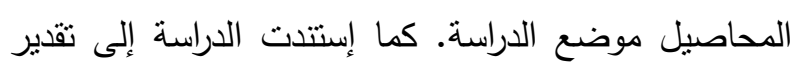

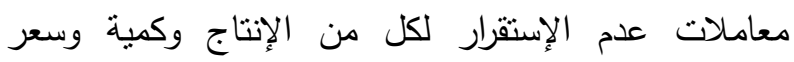

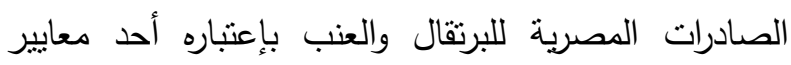

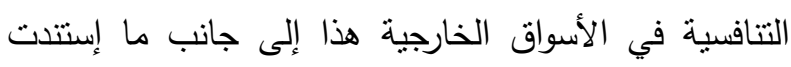
إليه الدراسة من تقدير لمختلف معايير التتافسية والتي تمنتل

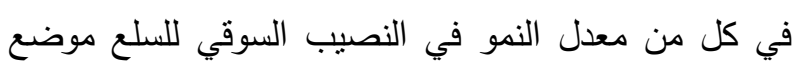

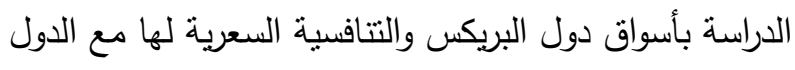
الهنافسة لهصر بنلالك الأسواق ومعدل إختراق الصادرات المصرية من البرتقال والعنب لتلاك الأسواق، والميزة النسبية الظاهرة لمصر في تصدير نللك المحاصيل وكذلك كفاءة أداء مصر للعمليات التصديرية. 
جدول 1. معالم معادلات الإتجاه العام الزمنى للمتغيرات الإقتصادية ذات التأثير على إنتاج البرتقال والعنب في مصر خلال الفترة (2005 - 2019)

\begin{tabular}{|c|c|c|c|c|c|c|c|}
\hline معدل النمو & المتوسط & $\mathbf{F}$ & $\mathbf{R}^{2}$ & معامل الإنحدار & ثابت الدالة & المتغير & \\
\hline 3.4 & 263.4 & $58.9^{* *}$ & 0.8 & $8^{* *}$ & 199.4 & ألف فدانة & \multirow{3}{*}{ البرتقال } \\
\hline 0.6 & 10.08 & $12.5^{* *}$ & 0.49 & $0.06^{* *}$ & 9.6 & طن/الإنتاجية & \\
\hline 3.6 & 2664.8 & $81.6^{* *}$ & 0.66 & $96.5^{* *}$ & 1892.5 & بالألف طن الإنتاج & \\
\hline 1.8 & 163.3 & $77.5^{* *}$ & 0.86 & $2.94^{* *}$ & 139.8 & ألف فدان & \multirow{3}{*}{ العنب } \\
\hline- & 9.25 & $2.16^{\mathrm{ns}}$ & 0.14 & $(0.04)^{\mathrm{ns}}$ & 9.5 & طن/فدان & \\
\hline 1.4 & 1509.9 & $12.76^{* *}$ & 0.33 & $21.78^{* *}$ & 1335.7 & بالألف طن الإنتاج & \\
\hline
\end{tabular}

الأرقام بين القوسين قيم سالبة

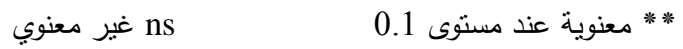

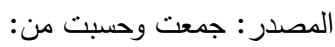

وزارة الزراعة واستصلاح الأراضى، قطاع الثئون الإقتصادية، نشرة الإحصاءات الزراعية، أعداد مختلفة.

كما أخذ الإنتاج المصري من البرتقال اتجاها تزايديا $\quad 204.9$ ألف طن إلى حوالي 117 ألف طن خلا فترتي الدراسة أي بنسبة 42.9\%.

كما يتضح أن صادرات مصر لإجمالي دول البريكس تزايدت نسبتها من إجمالي صادرات مصر لمختلف دول العالم من 22.4\% إلى 30.1\% للبرتقال ومن 7.2\% إلى 14.3 للعنب خلال فترتي الدراسة. وتنتحوذ روسيا على مالى الجانب الأكبر من صادرات مصر من البرتقال للبريكس خلال الفترة الأخيرة (2015-2019) بنسبة 67.6\% يليها الصين بنسبة 21.6\% والهند بنسبة 10.7\% في حين لم تمنل كل من البرازيل وجنوب أفريقيا أي أهمية نسبية تذكر لهرب في وارداتهما من البرتقال المصري. كما تستحوذ روسيا على الجانب الأكبر من صادرات مصر من العنب بأهمية نسبية من إجمالي صادرات مصر للبريكس بلغت حوالي 71.2 \%،
معنوي إحصائيا خلال فترة الدراسة مقداره 96.5 ألف طن سنويا وبمعدل نمو سنوي 3.6\% وأخذ العنب اتجاها تزايديا معنوي إحصائيا مقدار 21.8 ألف طن سنويا وبمعدل نمو سنوي 1.4\% من متوسط الإنتاج خلال فترة الدراسة. الأهمية النسبية لصادرات البرتقال والعنب المصري لدول

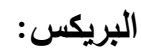

يتضح من جدول (2) أن إجمالي صادرات مصر من البرتقال لمختلف دول العالم نزايدت من حوالي 941.5 ألف هولف طن خلال متوسط الفترة (2010-2014) إلى حوالي 1151.5 ألف طن خلال متوسط الفترة (2015-2019) أي بنسبة 22.3\% في حين تراجعت نظيرتها للعنب من حوالي 
على التجارة الدولية في الفترة الأخيرة فإنه لا تستطيع الدول أن تعتمد في صادراتها من السلع الزراعية على الميزة النسبية فقط ولكن يجب أن تعرف كيف تحولها إلى ميزة تتافسية. وللتعرف على الموقف التنافسي لصادرات مصر من

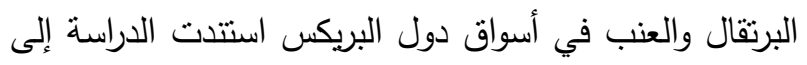

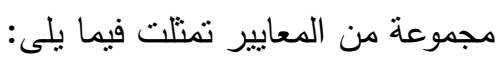
النصيب السوقي (Market share): بعتبر أحد المؤشرات التي تعكس حجم المبيعات الخارجية لأي دولة في سوق ما، حيث يشير النصيب السوقي على مدى وجود سوق حقيقي للبلد المصدر في البلد المستورد

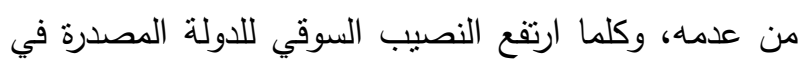
دولة استيراد السلعة كلما دل ذلك على النى ارتفاع القدرة التنافسية للاولة الدصدرة في ثلاك السوق.
يليها جنوب أفريقيا بأهمية نسبية 25.9\% في حين تضائلت الأهمية النسبية لباقى دول البريكس في وارداتها من العنب

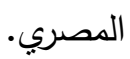

القدرة التنافسية للبرتقال والعنب المصري بأسواق دول

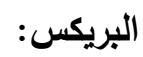
في ظل انساع نطاق التجارة الدولية وحرية التجارة وازالة

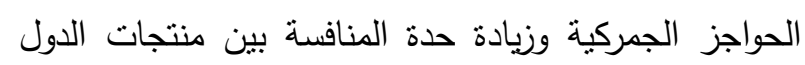

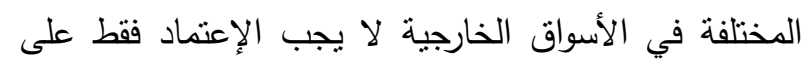

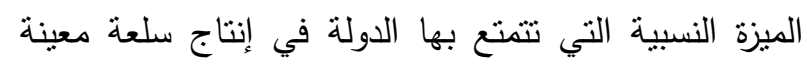
لكن يجب الإعتماد أيضا على القدرة التتافسية أو الميزة

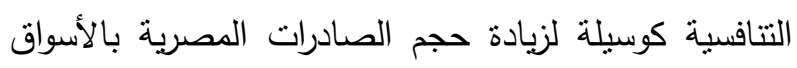
الخارجية. والميزة التنافسية لها مكونات معناها إنتاج سلعة بلة الهادية بتكلفة منخفضة وذات جودة عالية ووجود خدمات لتوصيل

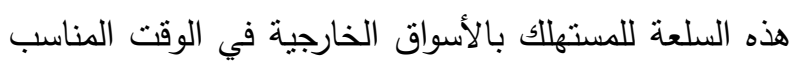

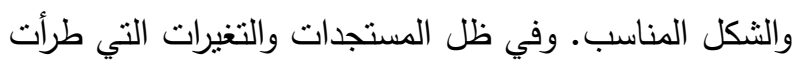

جدول 2. الأهمية النسبية للصادرات المصرية من البرتقال والعنب لاول البريكس خلال الفترتين(2010 - 2014)، (2015 -

\begin{tabular}{|c|c|c|c|c|}
\hline \multicolumn{2}{|c|}{ (الوحدة: ألف طن) } & & & 2019 \\
\hline & & & & البيان \\
\hline الفترة الثانية & الفترة الأولى & 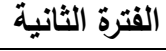 & 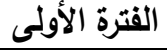 & \\
\hline 116.98 & 204.97 & 1151.54 & 941.51 & إجمالي صادرات مصر من المحصول للعالم \\
\hline 16.78 & 14.77 & 346.14 & 211.05 & الصادرات للبريكس \\
\hline 14.3 & 7.2 & 30.1 & 22.4 & \% للبريكس من إجمالي الصادرات \\
\hline 11.94 & 11.49 & 233.95 & 192.16 & صادرات المحصول لروسيا \\
\hline 71.2 & 77.7 & 67.6 & 91 & \% من إجمالي الصادرات للبريكس \\
\hline 0.19 & 0.69 & 74.93 & 1.73 & صادرات المحصول للصين \\
\hline 1.1 & 4.7 & 21.6 & 0.8 & \% من إجمالي الصادرات للبريكس \\
\hline 0.29 & 0.05 & 37.14 & 171.01 & صادرات المحصول للهند \\
\hline 1.8 & 0.4 & 10.7 & 8.1 & \% من إجمالي الصادرات للبريكس \\
\hline 0.003 & - & 0.02 & - & صادرات المحصول للبرازيل \\
\hline 0.015 & - & 0.004 & - & \% من إجمالي الصادرات للبريكس \\
\hline 4.35 & 2.55 & 0.10 & 0.06 & صادرات المحصول لجنوب إفريقيا \\
\hline 25.9 & 17.2 & 0.029 & 0.026 & \% من إجمالي الصادرات للبريكس \\
\hline
\end{tabular}

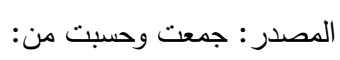

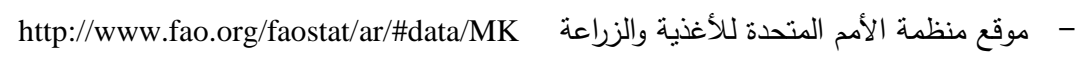

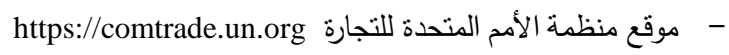


2.2 في كل من ثلاك السوقين على الترتيب في الفترة الثانية عن نظيره في الفترة الأولى، ونبين عدم وجود صادرات لمصر من العنب المصري للسوق البرازيلي خلال الفترة الأولى وضعفها خلال الفترة الثانية حيث بلغ النصيب السوقي للعنب المصري خلالهما قرابة 0.1\% . في حين إتسم النصيب السوقي للعنب المصري في السوق الصيني بالضآلة الثديدة خلال فترتي الدراسة حيث بلغ حوالي 0.04 في كلا الفترتين.

\section{التنافسية السعرية (Relative Price)}

تعتبر التتافسية السعرية من المحددات الأساسية والهامة في التأثثر على المركز التتافسي للسلعة في السوق العالمي حيث أنه كلما كانت الأسعار النسبية للسلعة المصدرة منخفضة، كلما دل ذللك على قوة المركز التتافسي للدولة في مواجهة الدول المنافسة في سوق السلعة، وتحسب التنافسية السعرية من المعادلة التالية:

السعر النسبى =100× سعر تصدير السلعة في دولة ما سير السلعة في الدولة المنافسة

التنافسية السعرية للبرتقال المصري في أسواق دول البريكس: - (ل)

يتضح من جدول (4) أن سعر تصدير الطن من البرتقال المصري للسوق الروسي خلال الفترة (2010 - 2019) قد تراوح بين حد أدنى بلغ نحو 265.7 دولار عام 2019 وحد أعلى بلغ حوالي 750.9 دولار عام 2012 وبمتوسط بلغ حوالي 444.4 دولار خلال فترة الدراسة. كما يتضح أن سعر تصدير البرتقال المصري لروسيا كان أقل من سعر تصدير الدول المنافسة له في هذا السوق وهي المغرب وتركيا وجنوب أفريقيا وذلك في غالبية السنوات
ويحسب النصيب السوقي من المعادلة التالية: $\mathrm{MSH}_{\mathrm{ji}}=\left(\mathrm{X}_{\mathrm{jci}} / \mathrm{M}_{\mathrm{cwi}}\right) \times 100$ حيث: من السلعة i في سوق النصيب السوقي للاولة :MSH

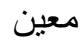
i من السلعة c صادرات الدولة j إلى الدولة X X i من دول العالم من السلعة c واردات الدولة: النصيب السوقي للبرتقال والعنب المصري في أسواق دول

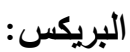

يتضح من جدول (3) أن السوق الروسي والسوق الصيني هي أكبر أسواق تكتل البريكس استيرادا للبرتقال خلال فترة الدراسة (2010-2019).

كما يتضح أن النصيب السوقي للبرتقال المصري في تلك الأسواق قد تزايد في السوق الروسي من حوالي 37.9\%

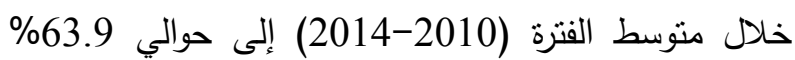
خلال منتسط الفترة (2015-2019) أي بنسبة 29.5\%، كما تزايد في السوق الصيني من 0.6\% إلى 13.4\%، ونزايد في السوق الهندي من حوالي 46.8\% إلى حوالي 81.1\% خلال فترتي المقارنة سالفة الذكر • في حين تبين عدم وجود صادرات لمصر من البرتقال للسوق البرازيلي خلال الفترة الأولى وضعفها خلال الفترة الثانية حيث بلغ النصيب السوقي للبرتقال المصري خلالهما قرابة 0.8\%. كما تراجع النصيب السوقي للبرتقال المصري بسوق جنوب أفريقيا من حوالي 4.3 إلى حوالي 3.1\% خلال فترتي الدراسة. كما بتضح ضعف النصيب السوقي للعنب المصري في أسواق تكتل البريكس خلال فترتي الدراسة (2010-2014)، (2015-2015) بإسنتناء سوق جنوب أفريقيا الذي بلغ نصيب العنب المصري فيه نحو 25.6\% خلال الفترة الأولى بلى وتزايد خلال الفترة الثانية إلى نحو 39.6\% من إجمالي واردات تلك السوق، كما يتضح تزايد النصيب السوقي للعنب المصري في السوق الهندي والسوق الروسي بنسبة 4.5\%، 
جدول 3. النصيب السوقي للبرتقال والعنب المصري في أسواق دول تكتل البريكس خلال الفترتين (2010 - 2014)، (2015 - 2019)

\begin{tabular}{|c|c|c|c|c|c|c|c|c|c|c|}
\hline \multicolumn{5}{|c|}{ العنب } & \multicolumn{5}{|c|}{ البرتقال } & \multirow{2}{*}{ 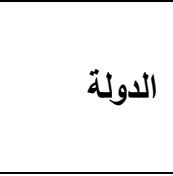 } \\
\hline النصديب تغير & \multicolumn{2}{|c|}{ النصبِ السوقى لمصر . } & \multicolumn{2}{|c|}{ كمية الواردات بالألف طن } & النصديب تغير & \multicolumn{2}{|c|}{ النصيب السوقي لمصر } & \multicolumn{2}{|c|}{ كمية الواردات بالألف طن } & \\
\hline- & 0.04 & 0.04 & 496.55 & 324.11 & 12.74 & 13.35 & 0.61 & 64.09 & 315.23 & الصين الصين \\
\hline 4.52 & 5.88 & 1.36 & 5.94 & 3.71 & 39.34 & 81.11 & 46.77 & 62.11 & 30.04 & الهند الهد \\
\hline \multirow{3}{*}{14.00} & & & & & & & & & \multicolumn{2}{|c|}{ الأرقام بين القوسين قيم سالبة } \\
\hline & & & & & & & & & 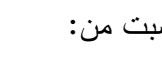 & المصدر : جمعت \\
\hline & & & & & & http://www.fa & g/faostat/ar/\# & $/ \mathrm{MK}$ & المتحدة للأغذي & - موقع منظمة - موقة \\
\hline
\end{tabular}


جدول 4. الميزة التنافسية للبرتقال المصري مع الدول المنافسة في أسواق دول بريكس خلال الفترة (2010- 2019)

\begin{tabular}{|c|c|c|c|c|c|c|c|c|c|c|c|c|c|c|}
\hline \multicolumn{3}{|c|}{ الهند } & \multicolumn{4}{|c|}{ الصين } & \multicolumn{3}{|c|}{ جنوب أفريقيا } & \multicolumn{4}{|c|}{ روسيا } & \multirow{3}{*}{ السنوات } \\
\hline \multicolumn{2}{|c|}{ النسبة السعرية مع مص } & \multirow{2}{*}{ مصر } & \multicolumn{3}{|c|}{ النسبة السعرية مع مصر * } & \multirow{2}{*}{ سعر مصر } & \multicolumn{2}{|c|}{ النسبة السعرية مع } & \multirow{2}{*}{ سعر مصر } & \multicolumn{3}{|c|}{ النسبة السعرية مع مصر * } & \multirow{2}{*}{ سعر مصر } & \\
\hline افزيقيا & امريكا & & افريقيا & امريكا & استراليا & & تركيا & اسبانيا & & افزويقيا & ت تركيا & المغرب & & \\
\hline 109.18 & 88.01 & 0.7033 & - & 15.78 & - & - & - & 75.89 & 0.5570 & 113.56 & 87.23 & 88.93 & 0.6177 & 2010 \\
\hline 89.79 & 90.60 & 0.5785 & 56.78 & 17.49 & 0.06 & 0.4008 & - & 69.47 & 0.6021 & 92.44 & 77.99 & 84.30 & 0.5456 & 2011 \\
\hline 122.99 & 114.05 & 0.7509 & 123.70 & 14.59 & 0.81 & 0.7509 & - & - & - & 145.90 & 113.73 & 134.09 & 0.7509 & 2012 \\
\hline 82.33 & 80.38 & 0.5218 & 81.03 & 11.98 & 2.95 & 0.5420 & - & 56.09 & 0.5379 & 104.51 & 76.69 & 88.61 & 0.4858 & 2013 \\
\hline 79.57 & 57.58 & 0.5028 & 77.20 & 5.07 & 4.26 & 0.5423 & 125.78 & 84.49 & 0.8218 & 106.93 & 80.46 & 85.27 & 0.4503 & 2014 \\
\hline 69.41 & 45.08 & 0.4222 & 78.48 & 6.93 & 5.19 & 0.5089 & 77.45 & 86.77 & 0.6129 & 86.30 & 76.37 & 94.06 & 0.4046 & 2015 \\
\hline 55.29 & 60.90 & 0.4140 & 59.92 & 9.33 & 6.38 & 0.4525 & 93.65 & 86.02 & 0.6793 & 77.94 & 76.42 & 102.30 & 0.3796 & 2016 \\
\hline 55.78 & 55.93 & 0.4714 & 58.94 & 6.44 & 7.06 & 0.5173 & 110.83 & 87.87 & 0.7156 & 70.08 & 88.94 & 120.72 & 0.4114 & 2017 \\
\hline 63.16 & 35.87 & 0.4609 & 63.05 & 5.43 & 8.05 & 0.5463 & - & 72.07 & 0.5991 & 82.07 & 103.58 & 62.50 & 0.4702 & 2018 \\
\hline 62.39 & - & 0.4241 & 104.24 & 3.02 & 6.35 & 0.4852 & 57.23 & 48.35 & 0.4125 & 49.94 & 50.39 & 31.92 & 0.2657 & 2019 \\
\hline 78.99 & 69.82 & 0.4663 & 78.15 & 9.61 & 4.57 & 0.5044 & 92.99 & 74.11 & 0.6180 & 92.97 & 83.18 & 89.27 & 0.4444 & المتوسط \\
\hline
\end{tabular}

* النسبة السعرية هي خارج قسمة سعر مصر على سعر كل من الدول المنافسة

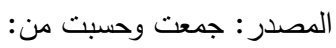

http://www.fao.org/faostat/ar/\#data/MK موقع منظمة الأمم المتحدة للأغذية والزراعة - منسة -

https://comtrade.un.org موقع منظمة الأمم المتحدة للتجارة - 
750.9 دولار عام 2012 وبمتوسط بلخ حوالي 466.3 دولار

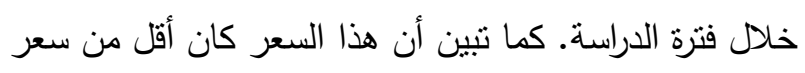
الدول المنافسة لمصر في هذا السوق وهي الولايات المنحدة

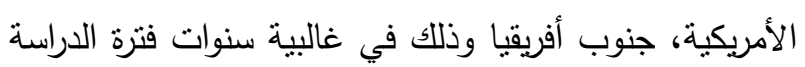

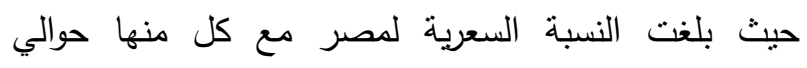
69.82\%، 78.99\% على التزتيب خلال متوسط الفترة (2010 - 2019) ويستدل من ذلك على وجود ميزة سعرية لللبرتقال المصري في السوق الهندي. التنافسية السعرية للعنب المصري في أسواق دول البريكس: يتضح من جدول (5) أن سعر تصدير الطن من العنب

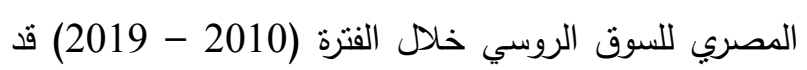
تراوح بين حد أدنى بلغ نحو 341.1 دولار عام 2011 وحد

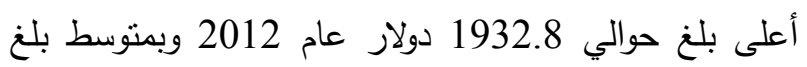

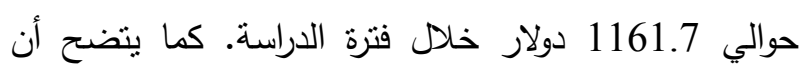

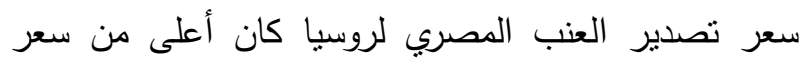

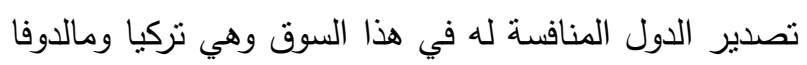

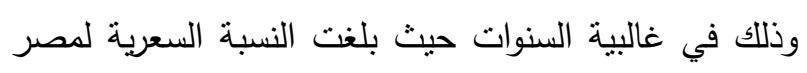
مع كل من تركيا وتنشيلى ومالدوفا في هذا السوق خلال

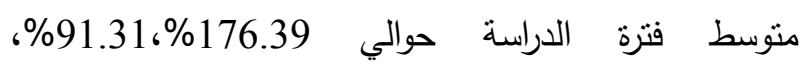
365.9\% على الترتيب وهو ما يشبر إلى عدم وجود ميزة سعرية للعنب المصري في السوق الروسي مع كل من تركيا ومالدوفا ولها ميزة سعرية مع تشيلى. لمئ.

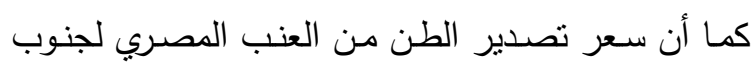
أفريقيا خلال الفترة (2010 - 2019) قد تراوح بين حد أدنى الطي الطي بلـغ نحو 335.4 دولار عـام 2011 وحد أعلى بلـغ حوالي 2804.6 دولار عـام 2013 وبمنوسـ بلـغ حوالي 1077.9 دولار خلال فترة الدراسة.
حيث بلغت النسبة السعرية لمصر مع كل من المغرب وتركيا وجنوب أفريقيا في هذا السوق خلال منوسط فترة الدراسة

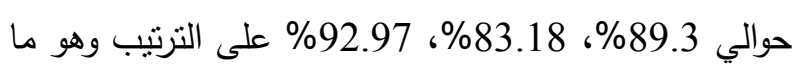

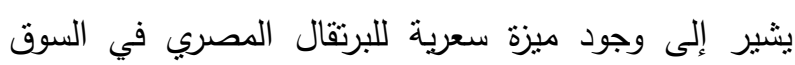
الروسي. ويتضح أن سعر تصدير الطن من البرتقال المصري

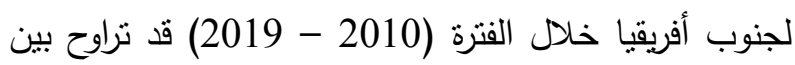

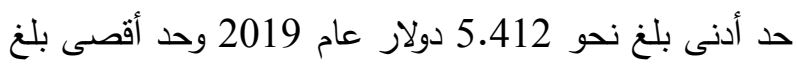
حوالي 821.8 دولار عام 2014 وبمتوسط بلغ حوالي 618 كاني دولار خلال فنرة الدراسة. كما تبين أن هذا السعر كان أقل من سعر الدول المنافسة لمصر في هذا السوق وهي أسبانيا، تركيا وذلك في غالبية سنوات فترة الدراسة حيث بلغت النسبة لهن النية

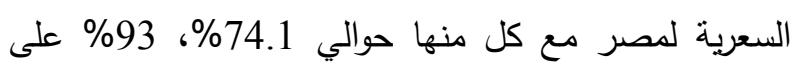
النزتيب خلال منوسط الفترة (2010 - 2019) ويستنل من من ذلك على وجود ميزة سعرية للبرتقال المصري في سوق

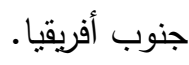
كما يتضح أن سعر تصدير الطن من البرتقال المصري

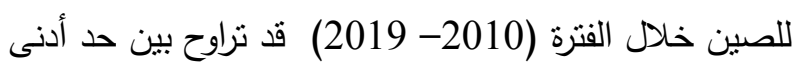

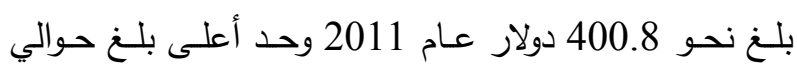
750.9 دولار عام 2012

وبمنوسط بلغ حوالي 504.4 دولار خلال فترة الدراسة. كما تبين أن هذا السعر كان أقل من سعر الدول الدنافسة لكصر في هذا السوق وهي أستراليا، أمريكا، جنوب أفريقيا

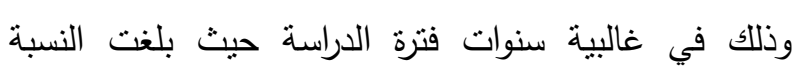

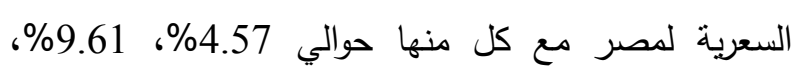

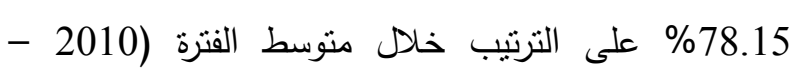
2019) ويستدل من ذللك على وجود ميزة سعرية للبرتقال المصري في السوق الصيني.

كما يتضح أن سعر تصدير الطن من البرتقال المصري

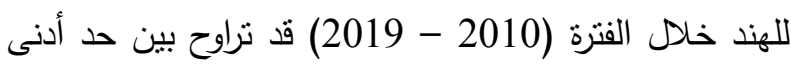
بلغ نحو 414 دولار عام 2016 وحد أقصى بلغ حوالي 
جدول 5. الميزة التنافية للعنب المصري والدول المنافسة مع دول بريكس خلال الفترة (2010- 2019)

\begin{tabular}{|c|c|c|c|c|c|c|c|c|c|c|c|c|c|c|c|c|}
\hline \multicolumn{4}{|c|}{ الهند } & \multicolumn{4}{|c|}{ الصين } & \multicolumn{4}{|c|}{ جنوب أفريقيا } & \multicolumn{4}{|c|}{ روسيا } & \multirow{3}{*}{ السنوات } \\
\hline \multicolumn{3}{|c|}{ النسبة السعرية مع مصر * } & \multirow{2}{*}{ مصر } & \multicolumn{3}{|c|}{ النسبة السعرية مع مصر * } & \multirow{2}{*}{ سعر مصر } & \multicolumn{3}{|c|}{ النسبة السعرية مع مصر * } & \multirow{2}{*}{ سعر مصر } & \multicolumn{3}{|c|}{ النسبة السعرية مع مصر ** } & \multirow{2}{*}{ سعر مصر } & \\
\hline الصين & بيرو & امريكا & & بيرو & تشيلى & استراليا & & ناميبيا & زامبيا & اسباتيا & & مالدوفا & تشيلى & تركيا & & \\
\hline 197.39 & 159.02 & 171.83 & 3.4040 & 52.20 & 56.09 & - & 1.2274 & 183.62 & - & 117.46 & 2.6456 & 339.94 & 112.85 & 175.69 & 1.6864 & 2010 \\
\hline 20.27 & 13.68 & 15.64 & 0.3354 & 119.32 & 142.46 & 133.14 & 2.9715 & 24.80 & - & 14.31 & 0.3354 & 62.52 & 22.18 & 45.08 & 0.3411 & 2011 \\
\hline 99.82 & 72.94 & 87.95 & 1.9328 & 13.04 & 15.82 & 12.95 & 0.3354 & 249.92 & - & 87.60 & 1.9328 & 402.25 & 121.81 & 240.08 & 1.9328 & 2012 \\
\hline 102.77 & 91.87 & 99.21 & 2.1410 & 71.26 & 100.74 & 82.83 & 1.9328 & 248.53 & - & 119.48 & 2.8046 & 407.85 & 111.23 & 187.86 & 1.8201 & 2013 \\
\hline 72.26 & 92.27 & 93.03 & 2.1317 & 83.72 & 93.58 & 81.91 & 2.0222 & 403.06 & 73.46 & 108.23 & 2.6869 & 434.72 & 100.99 & 225.42 & 1.7934 & 2014 \\
\hline 50.42 & 75.99 & 71.06 & 1.4659 & 79.67 & 86.87 & 75.47 & 1.6397 & 161.15 & 83.17 & 87.10 & 1.9069 & 474.52 & 105.82 & 196.66 & 1.6009 & 2015 \\
\hline 56.61 & 63.51 & 62.59 & 1.2177 & 61.42 & 74.26 & 50.45 & 1.1974 & 139.68 & 78.01 & 78.77 & 1.7350 & 424.08 & 84.95 & - & 1.2304 & 2016 \\
\hline 64.97 & 63.94 & 55.41 & 1.2416 & 105.09 & 103.55 & 71.56 & 1.9784 & 145.15 & 98.42 & 108.68 & 2.4762 & 390.47 & 85.25 & 183.82 & 1.3663 & 2017 \\
\hline 69.11 & 75.72 & 76.36 & 1.6437 & 88.68 & 117.19 & 75.40 & 2.0185 & 100.72 & 96.67 & 90.78 & 2.3227 & 397.88 & 85.22 & 186.11 & 1.3866 & 2018 \\
\hline 60.50 & 85.49 & 71.94 & 1.6808 & 105.93 & 120.69 & 82.10 & 2.1904 & 19.38 & - & 17.92 & 0.4470 & 324.81 & 82.83 & 146.76 & 1.2385 & 2019 \\
\hline 79.41 & 79.44 & 80.50 & 1.3560 & 78.03 & 91.13 & 73.98 & 1.0210 & 167.60 & 85.95 & 83.03 & 1.0779 & 365.90 & 91.31 & 176.39 & 1.1617 & المتوسط \\
\hline
\end{tabular}

* النسبة السعرية هي خارج قسمة سعر مصر على سعر كل من الدول المنافسة

المصدر : جمعت وحسبت من:

http://www.fao.org/faostat/ar/\#data/MK موقع منظمة الأمم المتحدة للأغذية والزراعة -

https://comtrade.un.org موقع منظمة الأمم المتحدة للتجارة - 


\section{Revealed Comparative advantage}

يعتبر معيار الميزة النسبية الظاهرة أحد معايير القدرة

التتافسية للسلع الزراعية في الأسواق الخارجية ويحسب هذاب

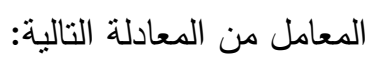

$\mathrm{RCA}=\frac{E i j / E j}{E i w / E w}$

RCA : معامل المبزة النسبية الظاهرة Eij : قيمة صادرات المحصول المصري : Eij Ej Eiw قيمة صادرات المحصول على مستوى العالم Ew واذا كانت قيمة هذا المؤشر أكبر من الواحد الصحيح دل ذللك على وجود ميزة نسبية لمصر وقدرة تتافسية للمحصول موضع الدراسة في الأسواق الخارجية والعكس صحيح. الميزة النسبية الظاهرة لمصر والدول المنافسة في تصدير

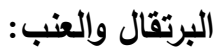

يتضح من جدول (6) أن أهم الدول المصدرة للبرتقال على مستوى العالم وتعتبر منافسة لمصر في الأسواق العالمية هي كل من أسبانيا والولايات المتحدة الأمريكية وجنوب أفريقيا. وقد بلغ متوسط قيمة مؤشر الميزة النسبية الظاهرة للبرتقال المصري في الأسواق الخارجية خلال فترتي الدراسة (2010-2014) (2015-2019) حوالي 31.4، 32.9 على الترتيب في حين بلغت قيمته لأسبانيا نحو 8.8، 7.6 على الترتيب وللولايات المتحدة الأمريكية نحو 1.22، 1.19 على الترتيب ولجنوب أفريقيا نحو 22.3، 21.3 على التزتيب. ويستدل من ذللك على تفوق البرتقال المصري في تلك الميزة عن الدول المنافسة له خلال فترتي الدراسة. كما يتضح أن تلك الميزة قد نزايدت لمصر في الفترة الثانية عن الفترة الأولى سالفة الذكر في حين نراجعت نلاك الميزة للدول المنافسة لمصر بمعدلات طفيفة في الفترة الثانية عن الفترة الأولى. ويستدل من ذلك على إرتفاع الميزة النسبية الظاهرة
كمـا تبين أن هذا السعر كان أقل من سـر الدول المنافسـة لمصر في هذا السوق وهي أسبانيا، زامبيا، ناميبيا وذلك في غالبية سنوات فترة الدراسة حيث بلغت النسبة السعرية لمصر مع كل منها حوالي 83.03\%، 85.95\%، 167.60\% على الترتيب خلال متوسط الفترة (2010 - 2019). ويستدل من ذلك على وجود ميزة سعرية للعنب المصري في سوق جنوب أفريقيا مع كل من أسبانيا وزامبيا وعدم وجود ميزة سعرية مع ناميبيا خلال متوسط فترة الدراسة. ويتضح أن سعر تصدير الطن من العنب المصري للصين خلال الفترة (2010 - 2019) قد تراوح بين حد أدنى مين بلغ نحو 335.4 دولار عام 2012 وحد أعلى بلغ حوالي 2971.5 دولار عام 2011 وبمتوسط بلغ حوالي 1021 دولار خلال فترة الدراسة. كما تبين أن هذا السعر كان أقل من سعر الدول المنافسة لمصر في هذا السوق وهي أستراليا، تنيلى، بيرو وذللك في غالبية سنوات فنرة الدراسة حيث بلغت النسبة السعرية لمصر مع كل منها حوالي 73.98\%، 91.13 \% \% 78.03 على الترتيب خلال متوسط الفترة (2010 - 2019) ويستدل من ذللك على وجود ميزة سعرية للعنب المصري في السوق الصيني. كما يتضح أن سعر تصدير الطن من العنب المصري

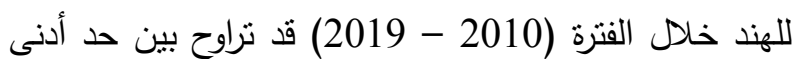
بلغ نحو 335.4 دولار عام 2011 وحد أعلى بلغ حوالي 3404 دولار عام 2012 وبمتوسط بلغ حوالي 1356 دولار خلال فترة الدراسة. كما تبين أن هذا السعر كان أقل من سعر الدول المنافسة لمصر في هذا السوق وهي الولايات المتحدة ، بيرو، الصين وذلك في غالبية سنوات فترة الدراسة حيث بلغت النسبة السعرية لمصر مع كل منها حوالي 80.5\%، 79.44\%، 79.41\% على الترتيب خلال متوسط الفترة (2010 - 2019) ويستخل من ذللك على وجود ميزة سعرية للعنب المصري في السوق الهندي. 
بمعدلات طفيفة في الفترة الثانية عن الفترة الأولى. ويستدل من ذلك على إرتفاع الميزة النسبية الظاهرة لمصر في تصدير البرتقال مقارنة بباقى الدول الدصدرة له على مستوى العالم

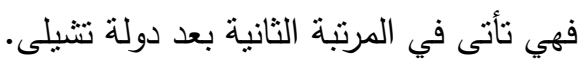

معدل إختراق السوق Market penetration Ratio: يعتبر معدل إختراق السوق لأي سلعة من أكثر المقاييس

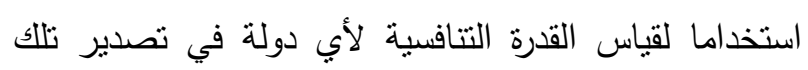
السلعة لأنه يمثل مقياس لددى إستيعاب الأسواق الخارجية

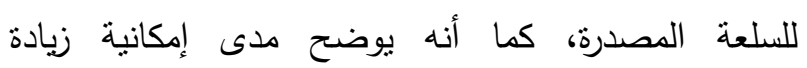

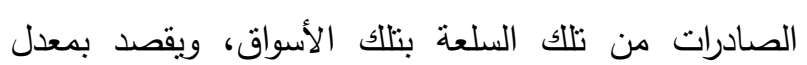

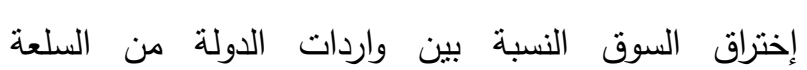

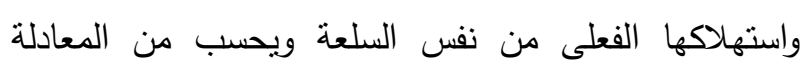

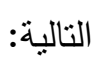

لهصر في تصدير البرتقال مقارنة بباقى الدول الدصدرة له على مستوى العالم. - ملي. ويتضح أن أهم الدول المصدرة للعنب على مستوى العالم

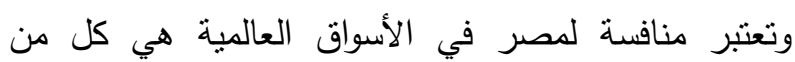

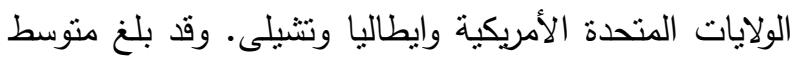

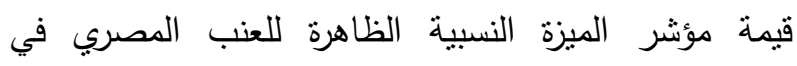
الأسواق الخارجية خلال فترني الدراسة (2010-2015-2019)

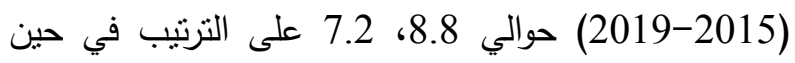
بلغت قيمته للولايات المتحدة الأمريكية نحو 1، 1.2018 على الئ

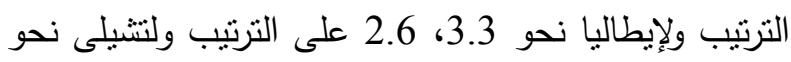

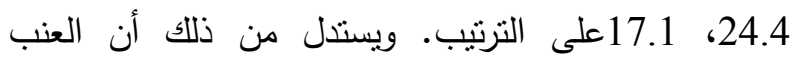
المصري يحتل المرتبة الثانية بعد دولة تثيلى المنافسة في تلك الميزة خلال فترتي الدراسة. كما يتضح أن نلك الميزة قد

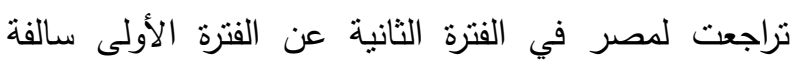

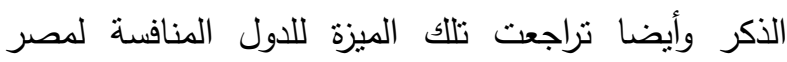

جدول 6. الميزة النسبية الظاهرة لمصر والدول المنافسة على مستوى العالم للبرتقال والعنب خلال الفترتين (2010-2014) و) وان(2015-2019)

\begin{tabular}{|c|c|c|c|c|}
\hline معدل التغير \% & الفترة الثانية & الفترة الأولى & الدولة & المحصول \\
\hline 4.59 & 32.9 & 31.4 & مصر & \multirow{4}{*}{ البرتقال } \\
\hline (12.84) & 7.6 & 8.8 & أسبانيا & \\
\hline (2.16) & 1.2 & 1.2 & أمريكا & \\
\hline (4.59) & 21.3 & 22.3 & جنوب أفريقيا & \\
\hline$(17.80)$ & 7.2 & 8.8 & مصر & \multirow{4}{*}{ العنب } \\
\hline (19.10) & 1.0 & 1.2 & أمريكا & \\
\hline (22.37) & 2.6 & 3.3 & إيطاليا & \\
\hline (29.97) & 17.1 & 24.4 & تشيلى & \\
\hline
\end{tabular}
http://www.fao.org/faostat/ar/\#data/MK موقع منظمة الأمم المتحدة للأغذية والزراعة -

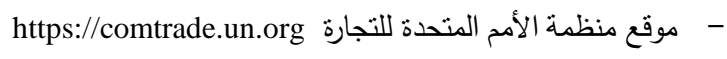


تحسن الموقف التتافسي لصالح مصر في الفترة الثانية بالنسبة للبرتقال في تلك السوق، كما تبين أن متوسط قيمة هذا المعامل للبرتقال المصري بأسواق جنوب أفريقيا، البرازيل،

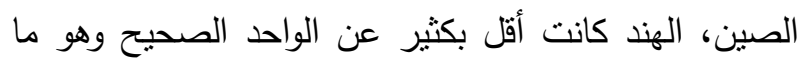

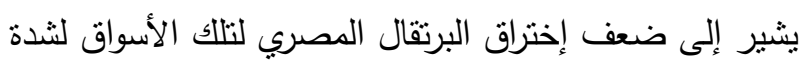
المنافسة فيها من الدول الأخرى وذلك خلال فترتي الدراسة. ويتضح من الجدول (7) أن متوسط قيمة معدل إختراق

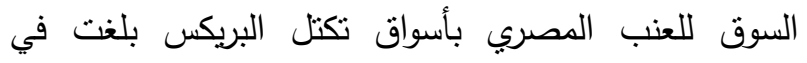
السوق الروسي حوالي 0.5، 0.3 خلال متوسط الفترتين (2010-2014)، (2015-2019) على الترتيب في حين قاربت قيم هذا المعدل من الصفر في أسواق جنوب أفريقيا،

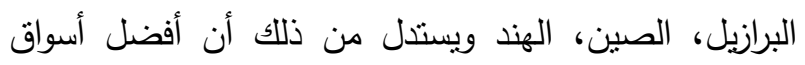
تكتل البريكس للعنب المصري من حيث معدل إختراق السوق هي السوق الروسي وتثير إبتعاد قيمة هذا المعدل في السوق

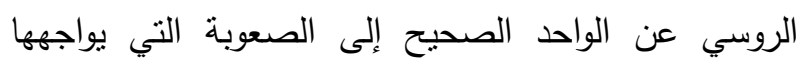
العنب المصري من حيث شدة المنافسة من الدول الأخرى لاسيما وأن قيمة هذا المعدل قد تراجعت في الفترة الثانية عن التحن

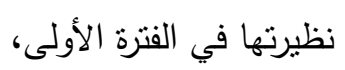

$\mathrm{MPRJ}=\frac{\mathrm{IJ}}{\mathrm{QJ}+\mathrm{IJ}-\mathrm{EJ}} * 100$

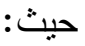

j معدل اختراق السوق في الدولة :MPRJ

إنتاج الدولة ز من السلعة في سنة ما :QJ

IJ

EJ صادرات مصر من السلعة للاولة j في نفس السنة

وتتزاوح قيمة هذا المؤشر بين الصفر والواحد الصحيح،

وكلما اقتربت نلك القيمة من الواحد الصحيح دل ذللك على الصى انساع السوق وسهولة إختراقه.

معل إخترق البرتقال والعنب المصري لأسواق دول إلهرول

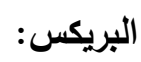

بتضح من جدول (7) أن قيمة معدل إختراق البرتقال

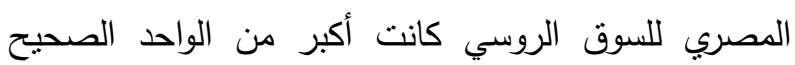
خلال فترتي الدراسة (2010-2014)، (2015-2019) مما لماري

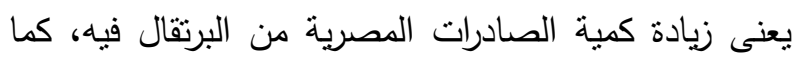
أن قيمة هذا المعدل قد نتزيدت خلال متوسط الفترة الثانية

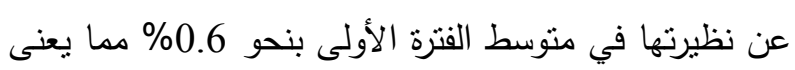

جدول 7. معدل اختراق السوق للبرتقال والعنب المصري بأسواق دول تكتل البريكس خلال الفترتين (2010-2014)، (2019-2015)

\begin{tabular}{|c|c|c|c|c|c|c|}
\hline الهند & الصين & البرازيل & جنوب أفريقيا & روسيا & البيان & المحصول \\
\hline 0.53 & 4.39 & 0.07 & 0.58 & 100.29 & الفترة الأولى & \\
\hline 0.75 & 6.60 & 0.12 & 1.01 & 100.89 & الفترة الثانية & البرتقال \\
\hline 0.22 & 2.21 & 0.06 & 0.43 & 0.60 & معدل التغير \% & \\
\hline 0.25 & 3.18 & 2.20 & 0.24 & 49.42 & الفترة الأولى & \\
\hline 0.22 & 3.69 & 1.65 & 0.50 & 32.21 & الفترة الثانية & العنب \\
\hline$(0.02)$ & 0.51 & $(0.55)$ & 0.25 & $(17.21)$ & معدل التغير" \% & \\
\hline
\end{tabular}

الأرقام بين القوسين قيم سالبة

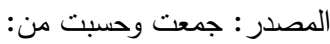
http://www.fao.org/faostat/ar/\#data/MK موقع منظمة الأمم المتحدة للأغذية والزراعة -

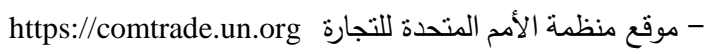


بلغ حوالي 12.82 عام 2015 وبمتوسط عام خلال فترة الدراسة حوالي 4.86 وهو ما يثبر إلى عدم إستقرار إنتاج

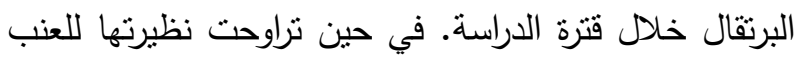

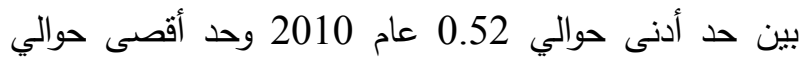
8.06 عام 2019 وبمتوسط عام خلال فترة الدراسة حوالي 44.43 وهو ما يشير إلى عدم إستقرار إنتاج العنب خلاد فنزرة الدراسة وارتفاع متوسط معاملات عدم إستقراره مقارنة بنظيرتها للبرتقال.

ويتضح أن قيمة معاملات عدم إستقرار كمية صادرات البرتقال الدصري تراوحت بين حد أدنى حوالي 1.67 عام 2018 وحد أعلى حوالي 35.48 عام 2012 وبمتوسط عام خلال فترة الدراسة حوالي 10.11 وهي تثتير إلى عدم إستقرار كمية صادرات البرتقال المصري خلال قتزة الدراسة. في حين تراوحت نظيرتها للعنب بين حد أدنى حوالي 0.94

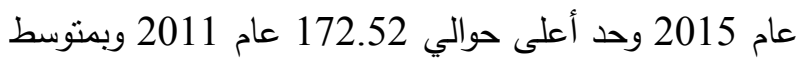
عام خلال فترة الدراسة حوالي 44.43 وهي تثتير إلى عدم

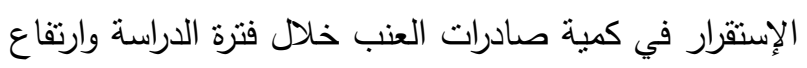
متوسط معاملات عدم إستقراره مقارنة بنظيرتها للبرتقال. كما يتضح أن قيمة معامل عدم إستقرار سعر تصدير البرتقال المصري تزروحت بين حد أدنى بلغ حوالي 0.32 عام

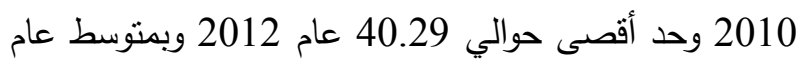
12.85 وهو يثير إلى عدم إستقرار أسعار تصدير البرتقال

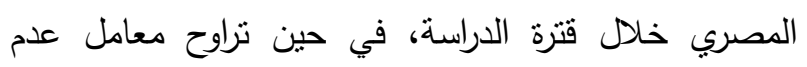
إستقرار سعر تصدير العنب بين حد أدنى حوالي 4.97 عام 2016 وحد أقصى حوالي 80.40 عام 2011 وبمتوسط عام المنام حوالي 22.46 خلال فترة الدراسة ويستدل من ذلك على شدة عدم الإستقرار في أسعار تصدير العنب مقارنة بنظيرتها

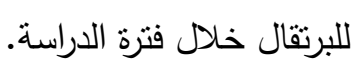

كما تشير إقتراب قيم هذا المعدل من الصفر في كل من أسواق جنوب أفريقيا والبرازيل والصبن والهند إلى شدة المنافسة وصعوبة إختراق العنب المصري لتلك الأسواق وصعوبة زيادة الصادرات المصرية من العنب فيها لاسيما

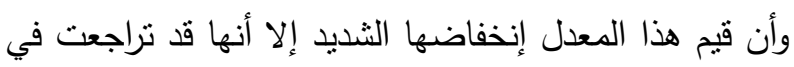
متوسط الفترة الثانية (2015-2019) عن نظيرتها في الفترة الأولى (2010-2014) في كل من البرازيل والهند.

معاملات عدم إستقرار(stability coefficient) إنتاج وصادرات البرتقال وإلعب المصري:

يعتبر معامل عدم الإستقرار من أكثر المقاييس استخداما

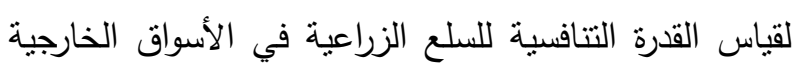

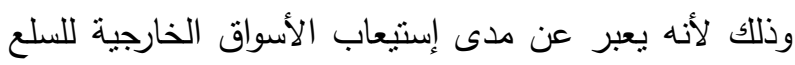
الدصدرة موضع الدراسة ومدى إمكانية زيادة الصادرات

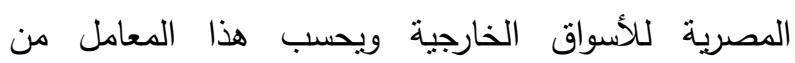

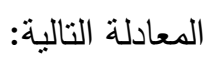

S.C $=\frac{\left|y i-y i^{A}\right|}{y i^{n}} * 100$

$$
\begin{aligned}
& \text { حيث: } \\
& \text { Sع : S.C } \\
& \text { i القيمة الفعلية للمتغير في السنه : Yi } \\
& \text { i القيمة التقديرية للمتغير في السنه في لون : yi^ } \\
& \text { || : تعنى عدم أخذ الإثارة الجبرية في الإعتبار }
\end{aligned}
$$


جدول 8. معاملات عدم استقرار إنتاج وصادرات البرتقال والعنب المصري خلال الفترة (2010 - 2019)

\begin{tabular}{|c|c|c|c|c|c|c|}
\hline \multicolumn{3}{|c|}{ العنب } & \multicolumn{3}{|c|}{ البرتقال } & \multirow[b]{2}{*}{ السنوات } \\
\hline معاملات سعر & معاملات كمية & معاملات كمية & معاملات سعر & معاملات كمية & معاملات كمية & \\
\hline 40.06 & 65.72 & 0.52 & 0.32 & 12.30 & 8.09 & 2010 \\
\hline 80.40 & 172.51 & 5.36 & 8.43 & 24.68 & 3.96 & 2011 \\
\hline 12.40 & 45.47 & 4.11 & 40.29 & 35.48 & 1.12 & 2012 \\
\hline 20.99 & 55.23 & 3.08 & 12.24 & 5.81 & 0.98 & 2013 \\
\hline 25.63 & 37.29 & 4.82 & 18.03 & 2.18 & 8.18 & 2014 \\
\hline 15.61 & 0.94 & 7.77 & 13.86 & 1.71 & 12.82 & 2015 \\
\hline 4.97 & 10.28 & 5.21 & 10.56 & 1.99 & 3.39 & 2016 \\
\hline 6.02 & 2.18 & 5.13 & 2.55 & 7.40 & 1.08 & 2017 \\
\hline 7.22 & 2.55 & 3.02 & 14.33 & 1.67 & 3.12 & 2018 \\
\hline 11.32 & 52.14 & 8.06 & 7.89 & 7.93 & 5.85 & 2019 \\
\hline 22.46 & 44.43 & 4.71 & 12.85 & 10.11 & 4.86 & المتوسط \\
\hline
\end{tabular}

- - وزارة الزراعة واستصلاح الأراضى ، قطاع الثئون الإقتصادية ، نشرة الإحصاءات الزراعية ، أعداد مختلفة.

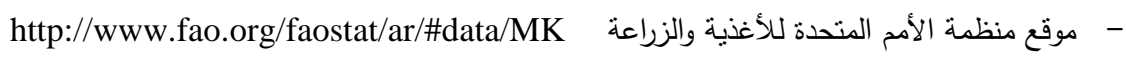

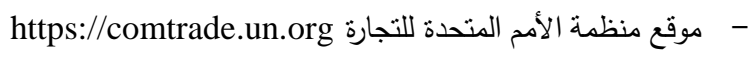

سالم، محمد حمدي- السعدني، محمد حسام- التجارة الدولية الزراعية، كلية الزراعة، جامعة عين شمس. على، سوزان عبدالمجيد أبو المجد- القدرة التنافسية للصادرات التهات

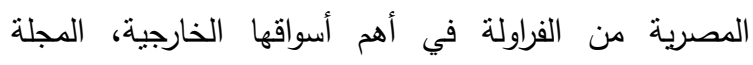

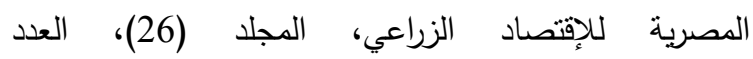

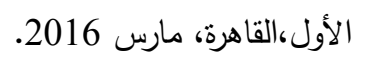
https://comtrade.un.org موقع منظمة الأمم المتحدة للتجارب اللتجارة

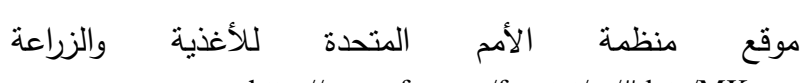
http://www.fao.org/faostat/ar/\#data/MK وزارة الزراعة واستصلاح الأراضي، قطاع الثئون الإقتصادية، نشرة الإحصاءات الزراعية، أعداد مختلفة.

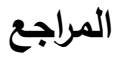

أحمد، صلاح الدين البهلول- دور مجموعة البريكس في الحوكمة العالمية، المجلة المصرية العلمية للاراسات التجارية والبيئية، جامعة قناة السويس، كلية التجارة بالإسماعيلية، المجلد (10)،

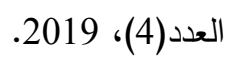

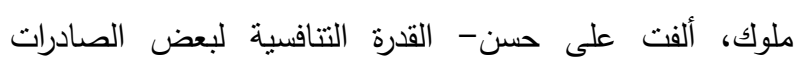

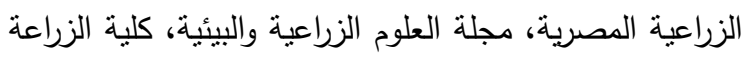

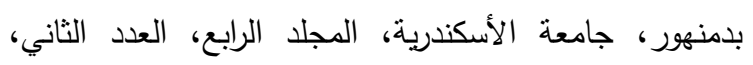
ديسمبر 2005.

الجهاز المركزي للتعبئة العامة والإحصاء، نثرة التجارة الخارجية، أعداد مختلفة. السيسي، صلاح الدين حسن - التجارة الدولية والصيرفة الإلكترونية

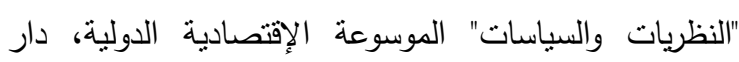
الكتب الحديث، 2014.

برغش، رانيا محمد- المزايا النسبية والنتافسية لأهم السلع الزراعية التهاء

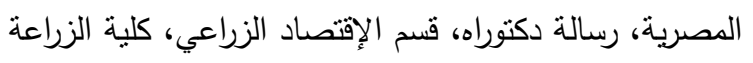

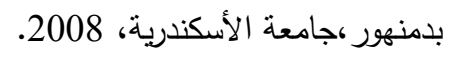




\title{
ABSTRACT \\ The competitiveness of the Most Important Egyptian Fruits in the Markets of the BRICS Countries
}

\author{
Azza Nabeeh Abdallah, Mostafa El-Saadany, Olfat Aly Melouk, Gaber Abdel Atty Mohamed
}

The main objective of this research was to identify the production situation of oranges and grapes in Egypt and the relative importance of Egyptian exports of them to the BRICS countries, and to estimate some of the competitiveness parameters for both crops within the BRICS's markets.

The competitive parameters for Egyptian oranges and grapes in the markets of the BRICS countries, clearly shows that the market share of Egyptian oranges in the markets of Russia, China, India, Brazil and South Africa amounted to about $63.9 \%, 13.3 \%, 81.1 \%, 0.1 \%$, $3.1 \%$ respectively, during the average period (20152019), while the market share of Egyptian grapes in each of them was about $5.2 \%, 0.04 \%, 5.9 \%, 0.01 \%$, $39.6 \%$, respectively, during the same period, which indicates a low market share for Egyptian oranges in The markets of Brazil and South Africa, as well as a low market share of Egyptian grapes in the markets of China and Brazil.

It is clear from the price competitiveness criteria that there is a price advantage for Egyptian oranges in the markets of the BRICS countries compared to the prices of the competing countries, namely Morocco, Turkey, South Africa, Spain, Australia and the United States of America, while it was found that there is no price advantage for Egyptian grapes in those markets compared to the prices of each of Turkey And Maldova, while it had a price advantage over the prices of Chilean grapes in the Russian market. In the South African market, it was found that there is a price advantage for Egyptian grapes compared to the prices of Spain and Zambia, and that there is no price advantage for it compared to the prices of Namibia. In the Chinese market, it was found that there is a price advantage for Egyptian grapes compared to the prices of grapes in Australia, Chile and Peru. In the Indian market, it was found that there is a price advantage for Egyptian grapes compared to the prices of American, Peruvian and Chinese grapes.

The results of the study indicate an increase in the value of Egypt's apparent comparative advantage factor in the export of oranges, estimated at about 23.9 during the average period (2015-2019), while its counterpart for the competing countries, namely South Africa, Spain, and the United States of America, amounted to about 21.3, 7.6, and 1.2, respectively. This coefficient of Egyptian grapes was about 7.2, while its counterpart for the competing countries, which are Chile, Italy, and the United States of America, was about 17.1, 2.6, and 1 respectively.

By estimating the market penetration rate of Egyptian oranges and grapes during the average period (2015-2019), it was found that its value is greater than one for Egyptian oranges in the markets of Russia, South Africa and China, which means the ease of penetration of Egyptian oranges to those markets, and less than one in the markets of Brazil and India, which means the difficulty of penetrating of the Egyptian oranges through those markets. It was also found that the value of the market penetration coefficient for Egyptian grapes is greater than the correct one during the same period in the markets of Russia and Brazil, which means that it is easy to penetrate those markets and it accounted for less than one in the markets of South Africa, China and India, which means that it is difficult to penetrate those markets. 